\title{
MAL MORAL E IGNORÂNCIA NA ÉTICA DE PLATÃo ${ }^{1}$
}

\author{
Reginald Hackforth \\ Sidney Sussex College, Cambridge
}

Tradução: Yasmin Tamara Jucksch²

Universidade de São Paulo (USP)

https://orcid.org/0000-0001-5444-9450

E-mail: yasmin99@usp.br

É universalmente aceito que Platão herdou de Sócrates, e manteve consistentemente até o fim, a doutrina de que nenhum homem faz o mal porque quer

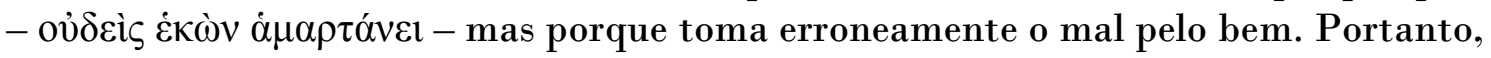
para Platão, todo mal moral envolve ignorância. No entanto, há duas passagens, uma no Sofista e outra em Leis IX, que parecem reconhecer um tipo de mal moral em que a ignorância não está envolvida, um tipo que é, na verdade, contrastado com aquele surgido da ignorância. Essas passagens não são certamente ignoradas pelos estudiosos: elas são regularmente referidas nas descrições mais conhecidas da teoria ética platônica. Ainda assim, não creio que tenham sido suficientemente consideradas, nem que representem uma resposta clara à questão se nesses diálogos tardios Platão pretende ou não, como parece pretender, uma modificação de sua doutrina ética anterior. Meu propósito é mostrar que ele não pretende, e demonstrar, se possível, a sua aparente contradição.

Em Sofista 227d o Estrangeiro de Eleia, que é comumente admitido como

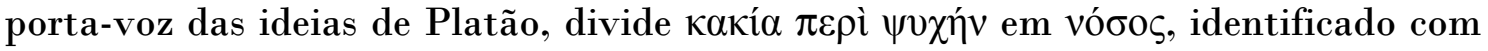

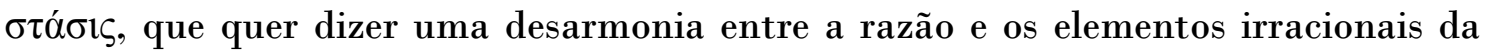

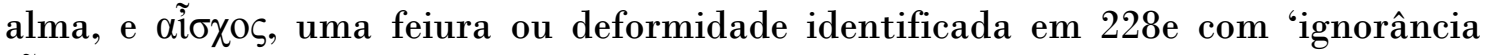
$(\tilde{\alpha} \gamma v o 1 \alpha)$ em suas muitas formas'. O primeiro tipo, que compreende $\delta \varepsilon \imath \lambda i \alpha, \dot{\alpha} \kappa о \lambda \alpha \sigma i \alpha$ e

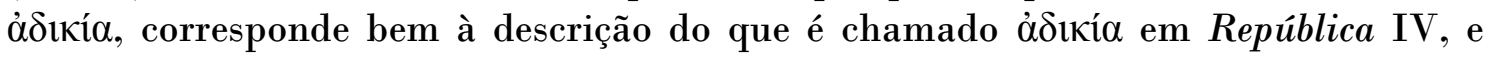
implica a doutrina da alma tripartida; mas deve-se notar que enquanto na República

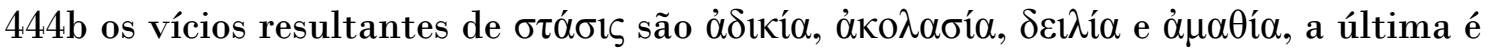

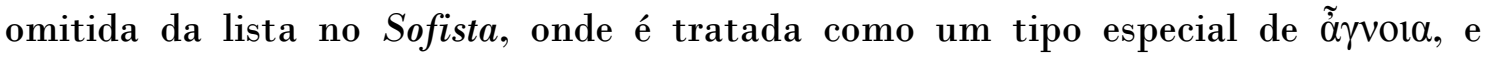
identificado (em sua forma extrema) com aquela "presunção de sabedoria" que a "Sofística Catártica" (isto é, o método socrático do elenchus) busca remover da alma.

Em Leis IX 863b ff. três tipos de $\alpha \mu \alpha \rho \tau \eta ́ \mu \alpha \tau \alpha$ são distinguidos, dos quais os

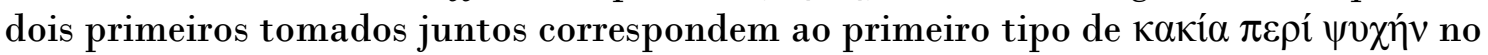

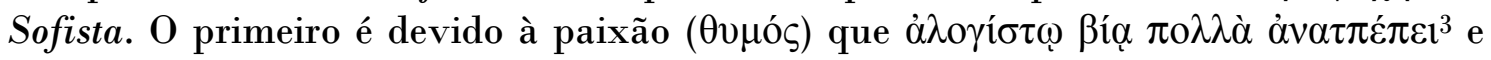

'Texto publicado originalmente em inglês, sob o título Moral Evil and Ignorance in Plato's Ethics. The Classical Quarterly, Vol. 40, n.3/4. Jul-Out, 1946, pp. 118-120 - Cambridge University Press. A tradução e a publicação foram autorizadas pela Cambridge University Press. O presente trabalho foi realizado com apoio da Coordenação de Aperfeiçoamento de Pessoal de Nível Superior - Brasil (CAPES) - Código de Financiamento 001.

2 Doutoranda em Filosofia na Universidade de São Paulo (USP), São Paulo - SP, Brasil. Bolsista do(a): Coordenação de Aperfeiçoamento de Pessoal de Nível Superior ( CAPES), Brasil.

${ }^{3}$ N. da T.: "perturba muitas coisas com sua força irracional." (PLATÃO. Leis 863b3. T. da T.).

HACKFORTH, Reginald. Mal moral e ignorância na ética de Platão. Tradução de Yasmin Tamara Jucksch. Griot : Revista de Filosofia, Amargosa - BA, v.19, n.2, p.343-346, junho, 2019. 
que é associado com a dor (864b), o segundo é devido ao prazer, o terceiro à ignorância $(\tilde{\alpha} \gamma v o t \alpha)$, que tanto pode ser simples ou aparecer em uma forma complexa

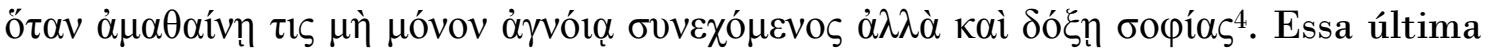

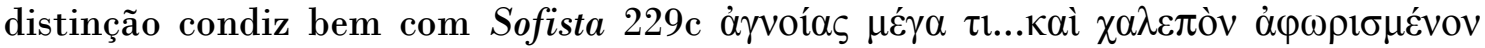

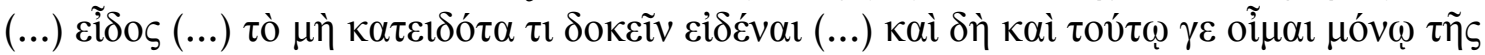

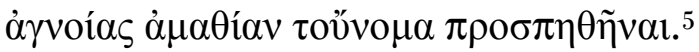

Assim, em ambos esses diálogos tardios nós encontramos Platão distinguindo a má ação devida à ignorância daquela devida à dominação do elemento racional pelo irracional. No entanto, é impossível acreditar que ele tenha sustentado que tal dominação não envolve ignorância, ou falta de discernimento moral; e, de fato, a

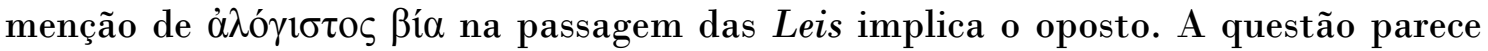
ser que, enquanto na República IV ele achou adequado reconhecer esse fato dizendo que tal dominação causa $\dot{\alpha} \mu \alpha \theta i ́ \alpha$ (bem como $\alpha \dot{\delta} \kappa_{\kappa}{ }^{\alpha} \alpha, \dot{\alpha} \kappa \circ \lambda \alpha \sigma i ́ \alpha$, e $\delta \varepsilon ı \lambda i ́ \alpha$ ), nos diálogos tardios ele prefere reservar $\dot{\alpha} \mu \alpha \theta i ́ \alpha$ e $\tilde{\alpha} \gamma v o 1 \alpha$ para essa falha de discernimento moral não como uma falha decorrente daquela dominação, mas como uma falha da razão per se. A questão é: por que ele prefere assim?

Eu sugiro que, mediante reflexão, sua doutrina em República IV lhe pareceu imperfeita em um particular. Lá ele havia tratado a faculdade racional ( $\tau$ ò

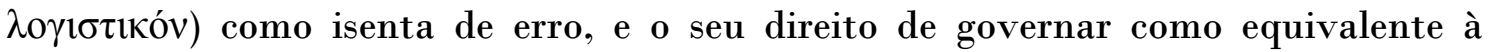
certeza de legislar corretamente ${ }^{6}$. Ele tinha imputado implicitamente, senão explicitamente, todo vício à supressão da razão por $\theta v \mu o ́ \varsigma$ e $\dot{\pi} \pi \imath v \mu i ́ \alpha$; inversamente, ele atribuiu toda virtude moral ao desempenho por cada parte da alma de sua função própria ${ }^{7}$. Mas agora que ele percebe esse defeito, ele o compensa da seguinte forma: ao invés de dizer que toda ignorância surge do excesso de paixão e desejo, ele diz que nenhuma efetivamente surge. Em outras palavras, o seu anseio em reconhecer o fato de que a razão erra per se o leva a obscurecer sua real crença, a saber, de que fazer o mal sempre envolve ignorância, seja a que for que ela se deva ${ }^{8}$.

Aliás, penso que está claro que nas Leis em todos os eventos Platão considera o tipo de má ação que surge da tirania do irracional como pior do que o outro tipo. Ele se recusa a permitir que o outro tipo mereça o nome de ádı́ía, muito

\footnotetext{
${ }^{4}$ Nota da T.: o erro pode ser devido tanto à "ignorância como à ilusão de sabedoria" (ibidem, 863c4-5).

${ }^{5}$ N. da T.: "Estrangeiro: Creio, pelo menos, distinguir uma forma especial de ignorância, tão grande e tão rebelde que equivale a todas as demais espécies. Teeteto: qual é ela? Estrangeiro: Nada saber e crer que se sabe; creio que aí esteja a causa de todos os erros aos quais o pensamento de todos nós está sujeito". Teeteto: É verdade. Estrangeiro: E é precisamente essa única espécie de ignorância que qualifica o nome de ignaro". (Tradução de Jorge Paleikat e João Cruz Costa. In: PLATÃ̃o. Sofista, 229cl-9. São Paulo: Abril, 1972, $1^{\text {a }}$ ed.).

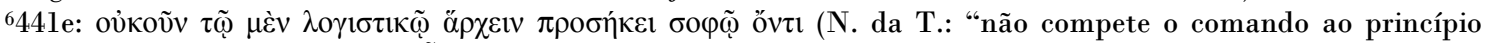
racional, por ser sábio?" PLATÃO. República, 44le. Tradução de Carlos Alberto Nunes. Belém: UFPA, 1973) e

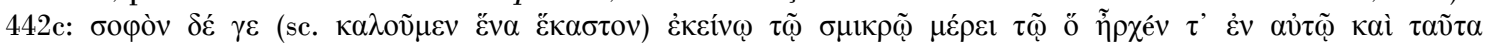

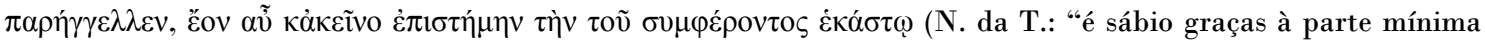
que nele exerce o mando e determina tudo aquilo, e, além disso, possui o conhecimento preciso do que é útil a cada parte". Ibidem, 442c).

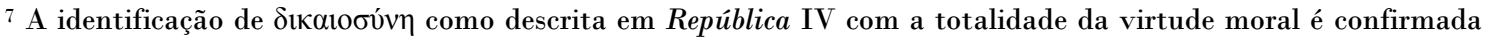

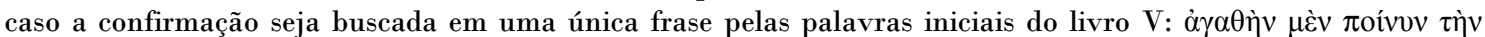

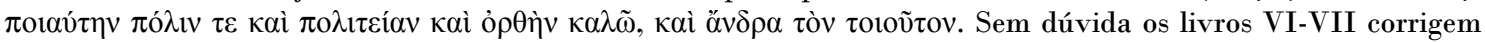
essa assertiva: eles mostram que um homem não é $\tau \varepsilon \lambda \varepsilon ́ \omega \varsigma$ $\alpha \gamma \alpha \theta$ ó que deveria ser: ela deve conhecer o Bem. Ainda assim, a presença de tais passagens como as indicadas em IV podem ter sido percebidas como equivocadas.

8 O problema do erro é um tópico frequente nos diálogos tardios; em acréscimo a Teeteto e Sofista ver especialmente Timeu 44b-c, 47b-c, 90d.
}

HACKFORTH, Reginald. Mal moral e ignorância na ética de Platão. Tradução de Yasmin Tamara Jucksch. Griot : Revista de Filosofia, Amargosa - BA, v.19, n.2, p.343-346, junho, 2019. 
naturalmente se ele estiver pensando em sua descrição de ódı́ía na República; e ele até mesmo chega ao ponto de dizer que qualquer ação praticada com a convicção de

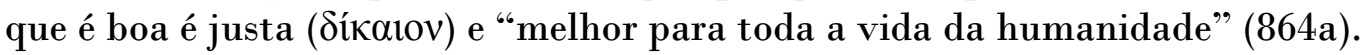

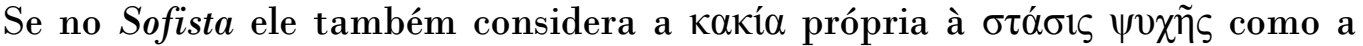
pior das duas, eu não acho eu possamos confirmar; mas ao menos não posso ver fundamento para a tese três vezes repetida do professor Grube de que o mal da ignorância é "muito mais fundamental"9. Realmente, ele é tratado como se tivesse maior extensão, mas isso é porque o propósito do contexto todo é elaborar a imagem do "Sofista" (ela é realmente, sem dúvida, uma imagem do Sócrates histórico) como

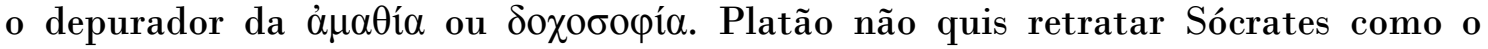

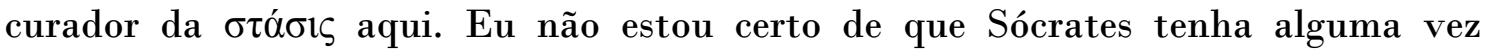
aparecido a ele sob essa luz; de qualquer forma, descrevê-lo aqui desse modo não seria o propósito de Platão: ele deve ser visto não como um físico, mas como educador, de modo que seu tipo de sofística possa ser alinhado (ironicamente) com aquele dos educadores profissionais.

O Timeu foi presumivelmente escrito antes das Leis IX, mas o que lá é dito sobre essa questão expressa melhor a doutrina real de Platão do que as passagens que viemos considerando. Em 86b, Timeu passa das doenças do corpo para as doenças da alma, com o propósito particular de mostrar como as primeiras causam as segundas (ou melhor, como podem causá-las, porque não está estabelecido que as doenças da alma não possam surgir de outra forma). É, portanto, bastante natural que vóбo̧ devesse ser usado aqui como o termo genérico, enquanto que no Sofista o

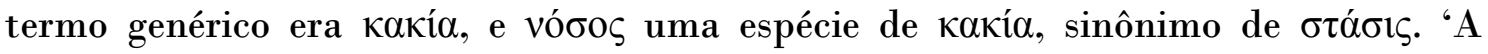
doença da alma, devemos admitir, é a loucura, e há dois tipos de loucura: demência e

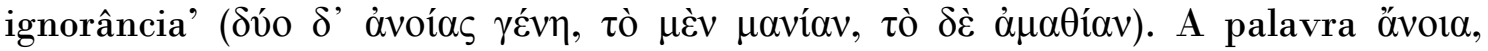
através da qual Platão aplica maior precisão ao termo genérico vóбos, corresponde de forma bastante aproximada à loucura nas suas associações. Diferente de á $\gamma v o 1 \alpha, o$ termo parece incluir maldade moral em um sentido mais estrito ( $\pi$ ovๆpía) além do intelectual, mas com uma preponderância de sentido tendendo para o último. Tratase de uma palavra bem escolhida para expressar a identidade genérica de $\mu \alpha v i ́ \alpha$ e $\alpha \mu \alpha \theta i ́ \alpha$. A descrição de $\mu \alpha v i ́ \alpha$ que se segue condiz com a descrição dos primeiros dois

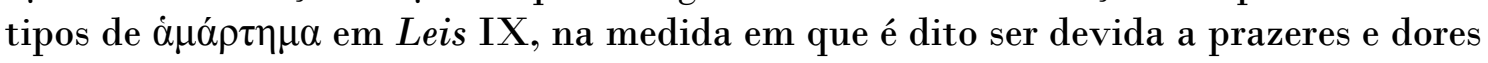
excessivos, mas no Timeu ele declara explicitamente o que não foi declarado nem em Leis IX nem no Sofista, ou seja, que mesmo nesse tipo de doença, que é distinguida

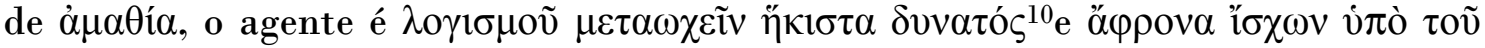

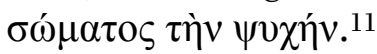

Há um aspecto enigmático da passagem do Sofista que eu deixei de lado até agora, para evitar que ele embaraçasse o meu argumento. $O$ segundo tipo de mal

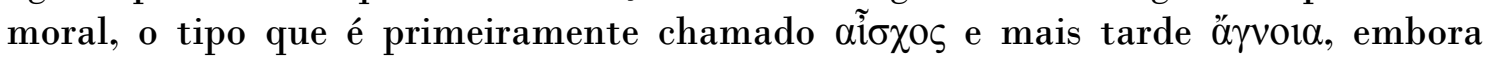
contrastado com $\sigma \tau \alpha ́ \sigma 1 \zeta$, parece envolver uma relação equivocada entre partes da

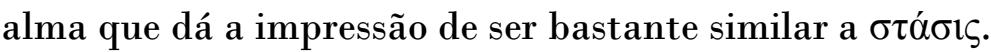

Em 228c o Estrangeiro diz:

\footnotetext{
9 Plato's Thought, pp. 226-7.

${ }^{10}$ Nota da T.: "rebaixado ao nível mais inferior em seu poder de raciocínio" (PLATÃO. Timeu, 86c3. T. da T.).

11 Nota da T.: "A alma é tornada insensata pelo corpo" (PLATÃO. Timeu, 86dl-2. T. da T).
}

HACKFORTH, Reginald. Mal moral e ignorância na ética de Platão. Tradução de Yasmin Tamara Jucksch. Griot : Revista de Filosofia, Amargosa-BA, v.19, n.2, p.343-346, junho, 2019. 
"Agora me diga: quando encontramos elementos que participam do movimento e que propõem a si mesmos um fim, e que buscam alcançá-lo mas são em cada tentativa desviados dele e falham em alcançá-lo, podemos dizer que isso acontece a eles por causa de uma proporção de um para com o outro, ou, pelo contrário, por causa de uma desproporção?

Teeteto: Claramente por causa de uma desproporção.

Estrangeiro de Eleia: Mas é claro que nós sabemos que qualquer alma que é ignorante de qualquer coisa não é ignorante voluntariamente.

Teeteto: Com certeza.

Estrangeiro de Eleia: Mas a ignorância se relaciona a uma alma que está voltada para a verdade, mas é desviada da compreensão, e isso é, na verdade, um desvio da razão ( $\pi \alpha \rho \alpha \varphi \rho \circ \sigma u ́ v \eta)$.

Teeteto: Certamente.

Estrangeiro de Eleia: Então a alma tola deve ser classificada como feia e malproporcionada.

Teeteto: Assim parece.

Pode-se esperar mais alguma luz de Timeu 87c-d, onde nós novamente ouvimos falar de $\sigma u \mu \mu \varepsilon \tau \rho^{\prime} \alpha$ e $\dot{\alpha} \mu \varepsilon \tau \rho i ́ \alpha$ em uma passagem que se propõe a sugerir remédios para doenças físicas surgidas de distúrbios corporais; e particularmente no

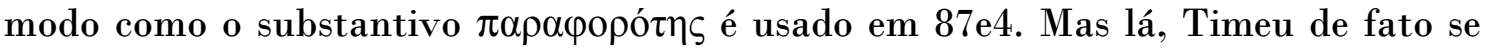
atém à proporção e desproporção entre alma e corpo, e não diz nada sobre uma desproporção na própria alma. Consequentemente, nós somos levados a assumir que na passagem do Sofista as partes da alma que podem ser $\sigma 0 \mu \mu \varepsilon \tau \rho \alpha$ ou $\dot{\alpha} \mu \varepsilon \tau \rho \alpha \pi \rho$ ò

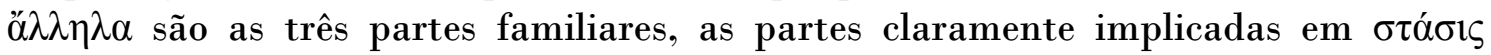
$\psi v \chi \tilde{\eta} \varsigma$ aqui. Evidentemente Platão deseja que nós vejamos uma real diferença entre

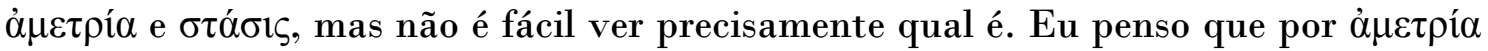
ele deve estar buscando descrever uma condição não de subjugação da razão pelo irracional, mas uma parcial (se não total) inabilidade da razão para funcionar - uma condição na qual não há conflito moral porque a razão ou nunca possuiu força suficiente, ou se tornou tão fraca que uma das duas partes irracionais, às vezes

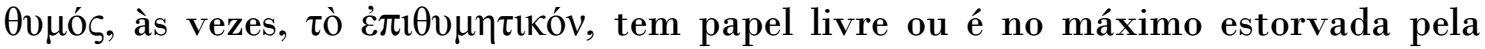
outra. Contudo, se essa sugestão é ou não compatível com a descrição da alma como

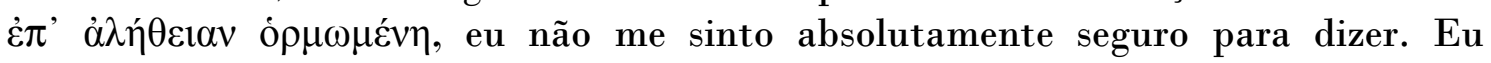
suponho que Platão poderia dizer que, por mais fracamente que nossa razão funcione, o verdadeiro eu que aspira à verdade e bondade persiste.

Autor(a) para correspondência: Yasmin Tamara Jucksch, Universidade de São Paulo, Av. Prof Luciano Gualberto, 315, Sala 1007, Conjunto Didático de Filosofia e Ciências Sociais - Cidade Universitária, 05508-010,São Paulo-SP, Brasil. yasmin99@usp.br 